\title{
EVALUASI PERFORMANCE LEAD APRON
}

\author{
Atin Nikmawati ${ }^{(1)}$ Siti Masrochah ${ }^{(2)}$ \\ ${ }^{1}$ Rumah Sakit Pertamina Balikpapan \\ ${ }^{2}$ Politeknik Kesehatan Kemenkes Semarang-Indonesia \\ Email : atinnikmawati@gmail.com
}

\begin{abstract}
Background : Lead apron is the most important part of set protection radiation personal in Radiology Instalation. Lead apron in Radiology instalation Roemani Muhammadiyah Semarang hospital had been test on 2014. But there is no test after that. The testing standard is 12-18 months at once or when it is needed, so this time the test should be done. This aim of the research are to know physical condition, lead apron profile, treatment and maintenance of lead apron, the result of the test and worthyness of lead apron.

Methods: The Type of this research is quantitative research with survey approach. Research use observation, testing, measuring and documentation. Observation done immediately toward the lead apron condition. Lead apron test also done by ilumination of all lead apron surface use $\mathrm{x}$-ray machine. The data from this research then checked with measuring crease, torn, crack, hole and inequality colour use software in computed radiography and desribed later.

Result: The result of the research indicate that the Lead Apron number 1 and 2 have bad condition and crack more than $15 \mathrm{~mm}^{2}$ in vital organ and more than $670 \mathrm{~mm}^{2}$ in non vital organ. Lead Apron number 3,4,5 have good condition, but has creases and some Lead Apron have inequality colour, Lead Apron number 6 has crease that cause a torn, but still in normal criteria. Lead Apron number 7 has a good condition with not crease.

Conclution: Two out of seven Lead Apron are declared not appropriate, dan five out of seven Lead Apron are declared appropriate, further can created Amount of Appropriate Lead Apron percentage which is five lead apron (71\%) in appropriate condition and two lead apron (29\%) in not appropriate condition.
\end{abstract}

Keyword : Performance, Lead Apron, Computed Radiography

\section{Pendahuluan}

Proteksi radiasi atau keselamatan kerja terhadap radiasi merupakan tindakan yang dilakukan untuk mengurangi pengaruh radiasi yang merusak akibat paparan radiasi. Perlengkapan proteksi radiasi yang biasa digunakan oleh pekerja radiasi adalah lead apron. Lead apron merupakan celemek timbal yang dirancang untuk melindungi tubuh dari bahaya radiasi (Yulihendra, 2002).

Upaya proteksi radiasi harus dilakukan dengan menerapkan 3 asas yaitu justifikasi, limitasi dan optimisasi. Prinsip dari asas optimisasi dikenal dengan sebutan ALARA (As Low As Resonably Achievable) demi meminimalisir paparan radiasi yang diterima pekerja radiasi tersebut. Prinsipnya adalah untuk mencegah bahaya radiasi dengan menjaga jarak pada tingkat yang aman pada sumber radiasi, membatasi waktu penyinaran dengan sesingkat mungkin dan menggunakan alat pelindung diri (Akhadi, 2000).

Alat pelindung diri (APD) adalah kelengkapan yang wajib digunakan saat bekerja sesuai bahaya dan resiko kerja untuk menjaga keselamatan pekerja itu sendiri dan orang di sekelilingnya. Alat pelindung diri yang digunakan pekerja radiasi selama berada di daerah radiasi adalah lead apron, Thyroid Shield, Gonad Shield, sarung tangan $\mathrm{Pb}$ dan kacamata google (Yulihendra, 2002).
Bahan utama yang digunakan untuk pembuatan alat pelindung diri tersebut adalah $(\mathrm{Pb})$ yang mampu menahan sinar-X. Ketebalan minimal pada lead apron tidak boleh dibawah $0,25 \mathrm{~mm}$ pada penyinaran sinar-X sampai $100 \mathrm{kV}$, disarankan bahwa ketebalan Lead Apron minimal harus $0,50 \mathrm{~mm}$. Ketebalan minimum kacamata google, Thyroid Shield, dan sarung tangan $\mathrm{Pb}$ adalah setara dengan ketebalan Lead Apron yaitu 0,50 mm (Grover S.B, 2002).

Dalam perawatan dan pemeliharaan alat pelindung diri perlu dilakukan dengan benar sehingga akan mengurangi terjadi kerusakan pada patahan internal. Penyimpanan yang tidak benar seperti meletakkan dengan cara dilipat dan ditumpuk, menggantungkan secara vertikal di lemari, menjatuhkan ke lantai, dapat mengurangi kualitas alat pelindung diri radiasi tersebut. Sebaiknya APD disimpan dalam almari dengan cara direntangkan secara horizontal dan tidak ditumpuk (Grover S.B, 2002).

Menurut Lambert dan Mc Keon (2001), pengujian lead apron dapat dilakukan 12-18 bulan sekali untuk melihat integritas dan kondisi fisik lead apron. Pengujian ini dapat dilakukan dengan menggunakan pesawat fluoroscopy atau secara radiograph, hasilnya lead apron tidak bisadigunakan lagi apabila kerusakan lebih dari $15 \mathrm{~mm}^{2}$ pada daerah yang vital dan kerusakan lebih dari $670 \mathrm{~mm}^{2}$ pada daerah non vital, jika kerusakan itu berupa garis atau patahan. Sedangkan 
menurut Lloyd (2001), pengujian lead apron dapat dilakukan 6 bulan sekali sesuai dengan kebutuhan. Lead apron diberi nomor identifikasi. Metode pengujian lead apron menggunakan fluoroscopy, film screen dan $C R$. Pengujian dilakukan untuk memperlihatkan adanya patahan, robekan, lubang dan kemrosotan lead apron. Jika lead apron sudah tidak layak, maka lead apron tidak dapat digunakan lagi. Kemudian laporkan lead apron yang tidak layak dengan menuliskan nomor identifikasi dan tanggal pengujiannya (Victorian, 2011).

Di Instalasi Radiologi Rumah Sakit Roemani Muhammadiah Semarang memiliki 7 buah lead apron. Dari 7 buah lead apron tersebut memiliki ciri-ciri yaitu : 2 diantaranya berwarna coklat dengan ketebalan sebesar $0,3 \mathrm{~mm} P b$ yang memiliki satu sisi, 1 lead apron berwarna biru muda dengan ketebalan $0,5 \mathrm{~mm} \mathrm{~Pb}$ yang memiliki satu sisi dan 4 lead apron berwarna biru donker dengan ketebalan $0,5 \mathrm{~mm} \mathrm{~Pb}$ yang memiliki dua sisi yaitu depan dan belakang. Lead apron tersebut 2 diantaranya dibeli pada tahun 1997, 3 lead apron dibeli pada tahun 2002,1 lead apron dibeli pada tahun 2011 dan 1 lead apron dibeli pada tahun 2017. Sejak awal dibelinya lead apron tersebut kecuali lead apron yang dibeli pada tahun 2017, sudah pernah dilakukan pengujian lead apron pada tahun 2014 oleh Pratama (Pratama, 2014) dengan menggunakan pengujian pesawat sinar-X fluoroscopy, hasil dari pengujian tersebut 2 diantaranya yaitu lead apron warna coklat dengan ketebalan $0,3 \mathrm{~mm} \mathrm{~Pb}$ memiliki lubang-lubang kecil dengan rincian nomor uji dua terdapat robekan pada bagian luar (kain luar) dan nomor uji empat terdapat garis menyerupai patahan pada bagian kiri atas. Robekan dan patahan tersebut tidak melebihi $670 \mathrm{~mm}^{2}$ sehingga masih dapat digunakan. Sedangkan 4 lead apron lainnya setelah diuji hasilnya tidak terdapat adanya kerusakan, sehingga lead apron masih layak digunakan. Hingga saat ini terdapat penambahan lead apron yang dibeli pada tahun 2017 dan belum dilakukan pengujian setelah pembelian lead apron tersebut. Sedangkan perawatan lead apron di Instalasi Radiologi Rumah Sakit Roemani Muhamadiyah Semarang berdasarkan observasi secara langsung peletakannya pada rak khusus, namun dalam penggunaan setelah pemeriksaan terkadang lead apron diletakan secara kurang benar, yaitu diletakkan diatas meja pemeriksaan yang salah satu sisi terkadang menggantung, diletakkan diatas pesawat mobile Sinar X atau diletakkan secara bertumpuk diatas brankard. Penggunaan Lead Apron di Instalasi Radiologi Rumah Sakit Roemani Muhammadiyah Semarang sering digunakan oleh radiolog dan radiografer saat melakukan pemeriksaan radiologi dengan menggunakan media kontras. Selain digunakan oleh radiolog dan radiografer, Lead Apron juga digunakan oleh keluarga pasien pada pemeriksaan tertentu seperti pada pemeriksaan pediatrik dan pasien non kooperatif.

Mengingat sudah 3 tahun dilakukan uji pada tahun 2014 dan penambahan lead apron yang saat ini belum diuji serta penggunaan lead apron setiap hari di Instalasi Radiologi Roemani Muhammadiyah Semarang, sesuai ketentuan 12-18 bulan sekali pengujian, maka saat ini perlu dikaji kembali kondisi lead apron tersebut.

\section{Metode}

Jenis penelitian yang dilakukan adalah penelitian kuantitatif dengan pendekatan survey. Lokasi pengambilan data adalah di Instalasi Radiologi Rumah Sakit Roemani Muhammadiyah Semarang. Waktu pengambilan data dilaksanakan mulai dari bulan Maret s/d Mei 2018. Sampel dari evaluasi performance lead apron meliputi 7 buah lead apron. Metode pengumpulan data dilakukan dengan observasi, dokumentasi dan pengukuran. Penelitian ini dilakukan dengan melakukan pengujian lead apron dengan menggunakan computed Radiography (CR) sesuai dengan langkah-langkah sebagai berikut:

1. Mendata seluruh lead apron yang akan diuji, kemudian diberi penomoran sebagai tanda agar tidak keliru dalam mecatat hasil

2. Untuk melihat performance lead apron dilakukan dengan membagi 4 kuadran pada lead apron sisi depan jika lead apron hanya memiliki sisi depan saja, dilakukan pembagian 4 kuadran sisi depan dan 4 kuadran sisi belakang bila lead apron memiliki sisi depan dan belakang.

3. Bentangkan lead apron diatas meja pemeriksaan dengan meletakan imaging plate berukuran $35 \mathrm{x}$ 43 dibawah lead apron pada masing masing kuadran secara bergantian.

4. Pesawat sinar-X diatur sebagai berikut :

a. Arah sinar vertikal tegak lurus.

b. Central point berada di pertengahan lead apron pada masing-masing kuadran.

c. $F F D: 100 \mathrm{~cm}$

d. Faktor eksposi : $70 \mathrm{kVp}$ dan $16 \mathrm{mAs}$.

5. Lakukan analisa atau pengukuran pada hasil gambaran jika terdapat retakan ataupun lubang dalam lead apron. Jika terlihat pada layar monitor Computed Radiography adanya retakan pada hasil gambaran, maka ditandai dengan adanya garis memanjang dengan warna hitam. Jika terdapat patahan maka ditandai dengan celah memanjang berwarna hitam, jika terdapat lekukan maka ditandai dengan adanya gambar seperti gelombang warna putih, jika terdapat lipatan maka ditandai dengan adanya gambar seperti gelombang warna putih yang superposisi. Dan jika terdapat lubang maka ditandai dengan gambar lingkaran warna hitam.

6. Lakukan pengukuran pada komputer dengan cara menggunakan menu measurement kemudian memilih line (garis) untuk mengetahui panjang retakan, lekukan, lipatan maupun lubang lead apron.

7. Cara pengukuran dengan line (garis) adalah membentuk garis yang menghubungkan titik terpanjang kerusakan sebagai lebar. Kemudian akan didapat nilai angka dari kerusakan lead apron tersebut.

8. Ulangi langkah-langkah tersebut untuk evaluasi lead apron selanjutnya.

9. Pengolahan dan analisa data yang dilakukan setelah observasi terhadap lead apron untuk mengetahui kondisi fisik, penanganan dan 
pemeriharaan lead apron. Hasil pegujian yang telah diperoleh selanjutnya diamati dan di bandingkan dengan teori lambert (2001), yaitu kerusakan tidak boleh melebihi dari $15 \mathrm{~mm}^{2}$ pada daerah yang vital dan kerusakan lebih dari 670 $\mathrm{mm}^{2}$ pada daerah non vital, jika kerusakan itu berupa garis atau patahan.

10. Daerah vital pada lead apron adalah area lead apron yang memiliki kerusakan melebihi 15 $\mathrm{mm}^{2}$ pada sekitar organ chest dan pelvis. Sedangkan daerah non vital adalah area lead apron yang memiliki kerusakan melebihi dari 670 $\mathrm{mm}^{2}$ di sepanjang lapisan, di area yang tumpang tindih atau pada area lead apron bagian belakang(Stanford University, 2018)

\section{Hasil dan Pembahasan}

Penelitian ini dilakukan dengan melakukan observasi pada seluruh lead apron di Instalasi Radiologi Rumah Sakit Roemani Muhammadiyah Semarang sejumalah 7 buah lead apron. Hasil spesifikasi dari ketujuh lead apron yaitu :

Tabel 1. Spesifikasi lead apron

\begin{tabular}{|c|c|c|c|c|c|}
\hline Kode & Merk & $\begin{array}{c}\text { Tahun } \\
\text { beli }\end{array}$ & $\begin{array}{l}\text { Kete } \\
\text { balan }\end{array}$ & Warna & Kondisi \\
\hline 1 & - & 1997 & $\begin{array}{c}0,3 \mathrm{~mm} \\
\mathrm{~Pb}\end{array}$ & Coklat & $\begin{array}{l}\text { Terdapat garis } \\
\text { menyerupai } \\
\text { retakan pada } \\
\text { lead apron dan } \\
\text { kerusakan } \\
\text { pada kain } \\
\text { pembungkus }\end{array}$ \\
\hline 2 & - & 1997 & $\begin{array}{c}0,3 \mathrm{~mm} \\
\mathrm{~Pb}\end{array}$ & Coklat & $\begin{array}{c}\text { Terdapat } \\
\text { retakan pada } \\
\text { sisi atas }\end{array}$ \\
\hline 3 & $\begin{array}{l}\text { Ward } \\
\text { ray }\end{array}$ & 2002 & $\begin{array}{c}0,5 \mathrm{~mm} \\
\text { Pb sisi } \\
\text { depan } \\
\text { belakang }\end{array}$ & $\begin{array}{c}\text { Biru } \\
\text { Donker }\end{array}$ & Baik \\
\hline 4 & $\begin{array}{l}\text { Ward } \\
\text { ray }\end{array}$ & 2002 & $\begin{array}{c}0,5 \mathrm{~mm} \\
\mathrm{~Pb} \text { sisi } \\
\text { depan } \\
\text { belakang }\end{array}$ & $\begin{array}{c}\text { Biru } \\
\text { Donker }\end{array}$ & Baik \\
\hline 5 & Kiran & 2011 & $\begin{array}{c}0,5 \mathrm{~mm} \\
\text { Pb sisi } \\
\text { depan, } \\
0,25 \mathrm{~mm} \\
\text { Pb sisi } \\
\text { belakang }\end{array}$ & $\begin{array}{c}\text { Biru } \\
\text { Donker }\end{array}$ & $\begin{array}{c}\text { Terdapat } \\
\text { beberapa } \\
\text { lekukan pada } \\
\text { permukaan }\end{array}$ \\
\hline 6 & $\begin{array}{l}\text { Prote- } \\
\text { X }\end{array}$ & 2017 & $\begin{array}{c}0,5 \mathrm{~mm} \\
\text { Pb sisi } \\
\text { depan, } \\
0,25 \mathrm{~mm} \\
\text { Pb sisi } \\
\text { belakang }\end{array}$ & $\begin{array}{c}\text { Biru } \\
\text { Donker }\end{array}$ & $\begin{array}{c}\text { Terdapat } \\
\text { lekukan pada } \\
\text { bagian bawah }\end{array}$ \\
\hline 7 & - & 2002 & $\begin{array}{c}0,5 \mathrm{~mm} \\
\mathrm{~Pb}\end{array}$ & $\begin{array}{l}\text { Biru } \\
\text { Muda }\end{array}$ & Baik \\
\hline
\end{tabular}

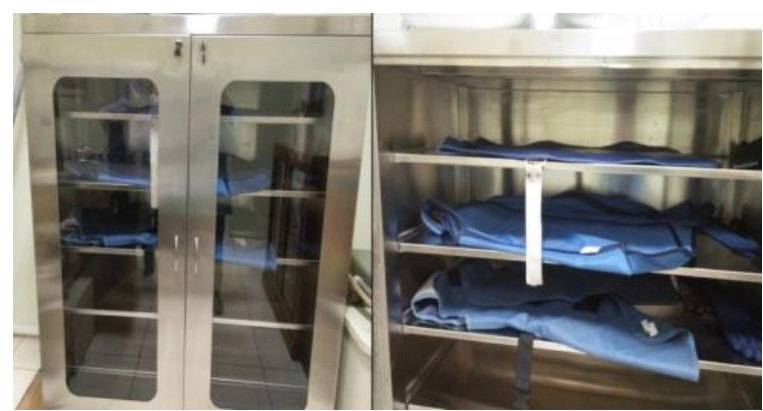

Gambar. 1 cara penyimpanan lead apron pada rak khusus

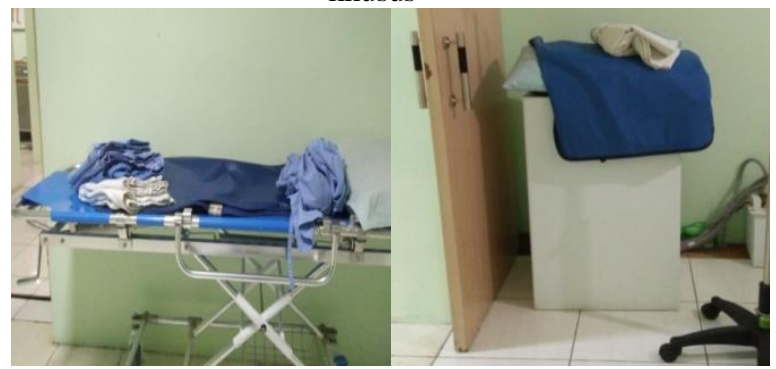

Gambar. 2 cara penyimpanan lead apron diatas brankard dan didalam ruang pemeriksaan

Cara pemeliharaan lead apron di Instalasi Radiologi Rumah Sakit Roemani Muhammadiyah Semarang tidak ada pemeliharaan secara khusus, hanya saja setelah pemeriksaan menggunakan kontras dan ada kontras yang tak sengaja menempel pada lead apron, dibersihkan dengan air biasa atau alkohol ke permukaan lead apron. Setelah itu di letakkan diatas brankard, meja pemeriksaan ataupun pada rak khusus. Jika lead apron tersebut diletakkan diatas brankard biasanya diletakkan secara bertumpuk dua sampai tiga lead apron. Jika diletakkan diatas meja pemeriksaan, ataupun diletakkan diatas pesawat mobile sinar-X. Hal ini bisa saja salah satu faktor yang dapat menjadi lead apron cepat rusak.

Berdasarkan hasil pengujian lead apron di Instalasi Radiologi Rumah Sakit Roemani Muhammadiyah Semarang, didapatkan hasil bahwa lead apron mengalami kerusakan berupa kerusakan internal maupun eksternal. Kerusakan internal berupa mayoritas lead apron memiliki banyak lekukan dan warna lead apron yang tidak merata. Sedangkan kerusakan eksternal berupa adanya noda pada lead apron dan robekan pada kain luar. Menurut penulis berdasarkan hasil pengujian yang sudah ada, hal tersebut dapat dikarenakan pemeliharaan berupa perawatan dan penyimpanan yang kurang tepat, seperti menjatuhakannya di lantai, meletakkan lead apron secara bertumpuk dan tidak diletakkan pada bidang datar atau rak khusus. Sehingga menyebabkan kerusakan pada lead apron secara internal berupa lekukan, patahan, robekan, warna lead apron yang tidak homogen dan lubang lead apron. Sedangkan kerusakan eksternal berupa noda media kontras dan robekan pada kain pembungkus dapat disebabkan karena pembersihan lead apron yang kurang tepat. Hal ini perlu diperhatikan karena hal tersebut dapat mengurangi estetika performance lead apron. Sebaiknya, untuk perawatan lead apron perlu dibersihkan secara rutin dengan menggunakan air saja maupun menggunakan air sabun dengan cara dilap. Agar kain pembungkus tidak mudah 
JURNAL RADIOGRAFER INDONESIA, ISSN 2620-9950

sobek. Perawatan juga dapat dilakukan secara berkala setiap hari untuk menjaga lead apron dalam kondisi bersih menggunakan air biasa ataupun air sabun menggunakan kuas atau sikat yang berbulu halus. Sebaiknya dibuat pula poster yang berisi tentang bagaimana cara penanganan dan pemeliharaan lead apron yang benar, kemudian ditempelkan pada dinding ruang pemeriksaan.

Adanya standar operasional prosedur (SOP) tentang proteksi radiasi untuk pasien dan standar operasional prosedur (SOP) tentang proteksi radiasi bagi lingkungan di Instalasi Radiologi Rumah Sakit Roemani Muhammadiyah Semarang, sudah menjadi point bagus dalam upaya keselamatan proteksi radiasi yang dilakukan pada rumah sakit. Sehingga pelayanan dapat berjalan lebih maksimal.

Pengujian lead apron dilakukan dengan menggunakan faktor eksposi $70 \mathrm{kV}$ dan 16 mAs. Didapatkan hasil pengujian lead apron dengan berbagai macam kerusakan seperti retakan, lubang, warna lead apron yang tidak homogen, lekukan, lipatan.

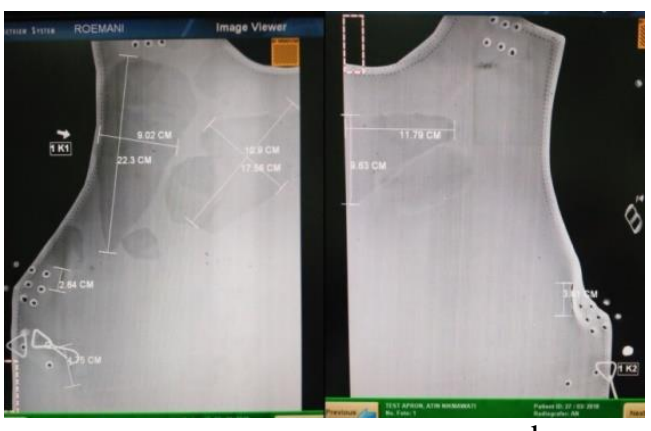

b

Gambar. 3Hasil pengujian lead apron 1

(a)Kuadran 1 (b) Kuadran 2, tampak adanya kerusakan berupa retakan dan warna lead apron yang tidak homogen.

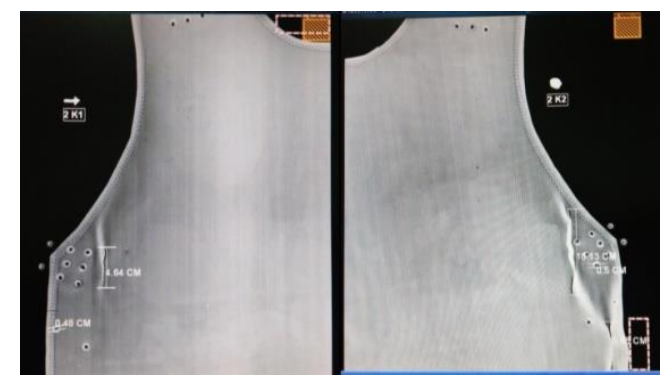

a b

Gambar. 4 hasil pengujian lead apron 2

(a)Kuadran 1(b) Kuadran 2, tampak adanya kerusakan berupa retakan dan warna lead apron yang tidak homogen.

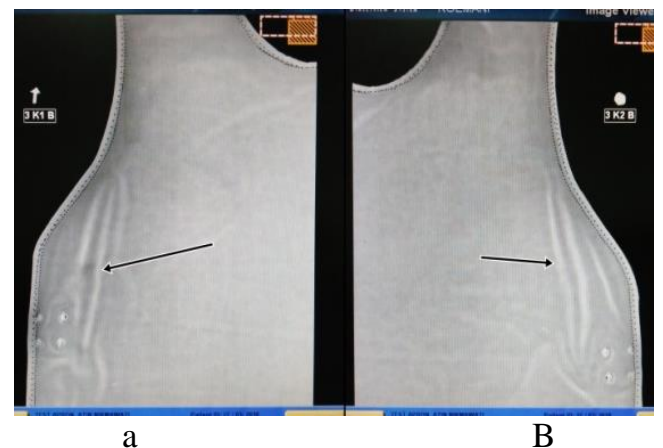

Gambar.5 hasil pengujian lead apron 3 bagian belakang (a)Kuadran 1 (b) Kuadran 2, tampak adanya lekukan

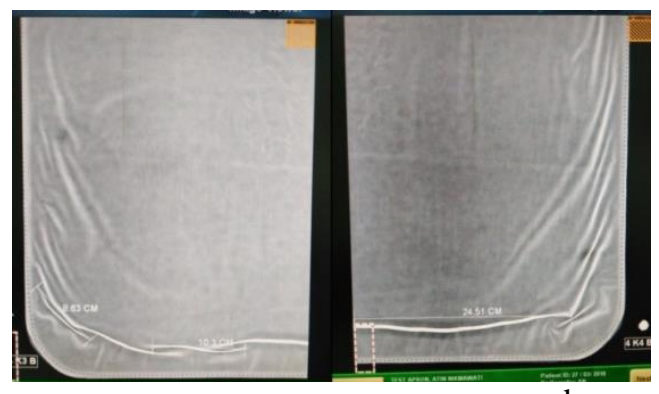

b

Gambar.6 Hasil pengujian lead apron 4 bagian belakang

(a) Kuadran 3 dan (b) kuadran 4 tampak adanya lekukan dan lipatan

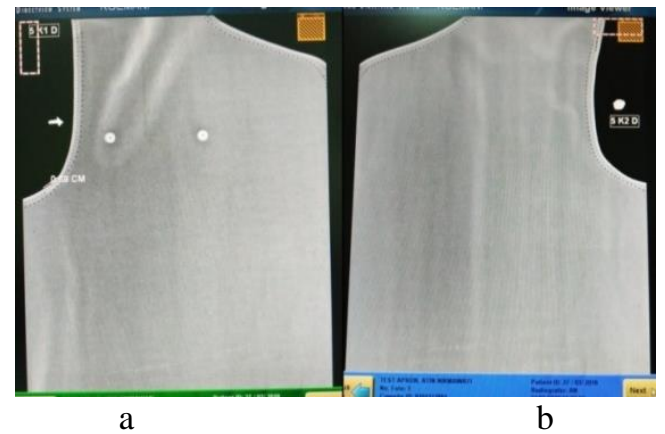

Gambar.7 Hasil pengujian lead apron 5 bagian depan (a) Kuadran 1 tampak adanya robekan akibat jahitan dan (b) kuadran 2.

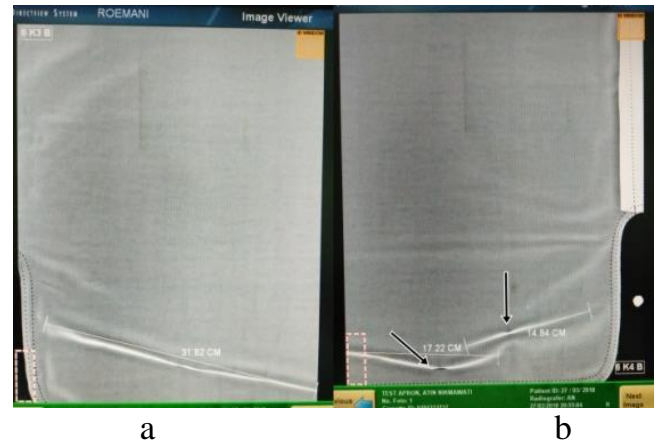

Gambar.8 Hasil pengujian lead apron 6 bagian belakang

(a) Kuadran 3 tampak adanya lipatan dan (b) kuadran 4 tampak adanya lipatan yang mengakibatkan adanya robekan. 


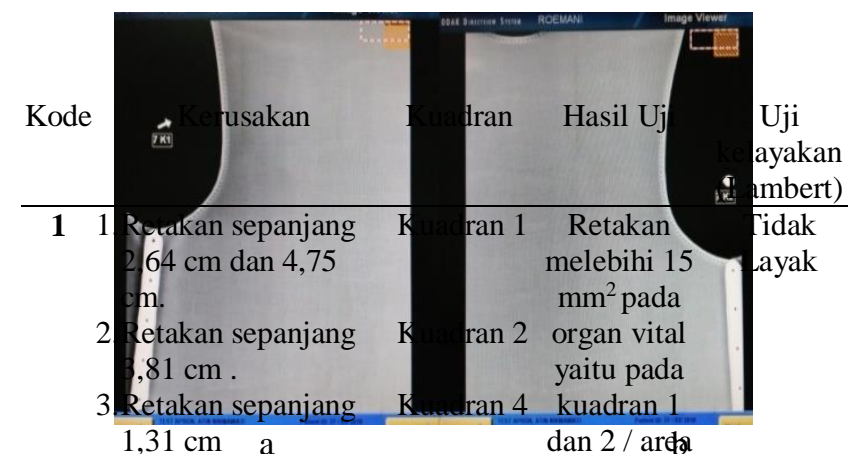

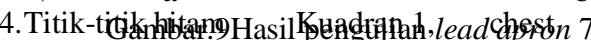
(dgrKWaAn apron tidak kerusakan.

homogen.

5.Lubang besi dengan Kuadran1, diameter $0,5 \mathrm{~cm}$. 2

2 1.Retakan sepanjang Kuadran 1 Retakan Tidak $4,64 \mathrm{~cm}$ melebihi,15 layak 2. Rerdasarkan hasil Renguijan dar paread apron, maka pgpatchibuat tabod kelayakan legrgapkphy yaitu : $\mathrm{cm}$ yaitu pada

3.Lubang besi dengan Kuadran 1, kuadran 1 diameter $0,5 \mathrm{~cm} \quad 2$ dan $2 /$ area

4. Titik-titik hitam Kuadran 1, chest dan Warna lead 2,3,4 apron tidak homogen

Lubang lead apron, masih dalam batas normal

\begin{tabular}{|c|c|c|c|}
\hline 3 & $\begin{array}{l}\text { 1.Lekukan lead } \\
\text { apron } \\
\text { 2. Titik-titik hitam } \\
\text { pada lead apron }\end{array}$ & $\begin{array}{l}\text { Kuadran 1, Lekukan, } \\
\text { kuadran } 2 \text { masih dalam } \\
\text { depan batas normal } \\
\text { Kuadran1, } \\
\text { 2, 3, dan } 4 \\
\text { Belakang. } \\
\text { Kuadran } 3\end{array}$ & Layak \\
\hline 4 & $\begin{array}{l}\text { 1.Lekukan sepanjang } \\
\text { 28,29 cm } \\
\text { 2.Lekukan sepanjang } \\
\text { 39,24 cm } \\
\text { 3.Lekukan sepanjang } \\
\text { 30,15 cm dan } 27,37 \\
\mathrm{~cm} \\
\text { 4.Lipatan sepanjang } \\
\text { 8,63 cm dan } 10,3 \\
\mathrm{~cm} \\
\text { 5. Lipatan sepanjang } \\
\text { 24,51 cm } \\
\text { 6. Lubang besi dengan } \\
\text { diameter } 0,5 \mathrm{~cm}\end{array}$ & $\begin{array}{cc}\text { Kuadran } 1 & \text { Lekukan, } \\
\text { depan } & \text { Lipatan dan } \\
\text { Kuadran } 2 & \text { lubang pada } \\
\text { depan } & \text { lead apron } \\
\text { Kuadran } 3 & \text { masih dalam } \\
\text { depan } & \text { batas normal }\end{array}$ & Layak \\
\hline 5 & $\begin{array}{l}\text { 1. Robekan sepanjang } \\
0,36 \mathrm{~cm} \\
\text { 2.Lekukan lead } \\
\text { apron }\end{array}$ & $\begin{array}{cc}\begin{array}{c}\text { Kuadran } 1 \\
\text { depan }\end{array} & \begin{array}{c}\text { Lekukan, } \\
\text { robekan }\end{array} \\
\text { Kuadran 2, masih dalam } & \text { mas normal } \\
3 & \text { batas no } \\
\text { belakang, } & \end{array}$ & Layak \\
\hline 6 & $\begin{array}{l}\text { 1. Robekan karena } \\
\text { lipatan sepanjang } \\
1,5 \mathrm{~cm} \text { dan } 0,85 \\
\mathrm{~cm} . \\
\text { 2.Lipatan sepanjang } \\
\text { 31,82 cm } \\
\text { 3.Lipatan sepanjang } \\
\text { 17,22 cm dan } 14,84 \\
\mathrm{~cm} \\
\text { 4.Lekukan sepanjang } \\
\text { 39,02 cm } \\
\text { 5. Warna lead apron } \\
\text { tidak homogen }\end{array}$ & 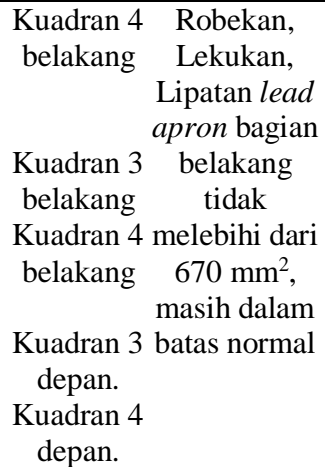 & Layak \\
\hline 7 & $\begin{array}{l}\text { Warna lead apron } \\
\text { tidak homogen }\end{array}$ & $\begin{array}{l}\text { Seluruh } \\
\text { kuadran }\end{array}$ & Layak \\
\hline
\end{tabular}

Hasil pengujian dari ketujuh lead apron tersebut yaitu, Lead apron 1 mengalami kerusakan berupa retakan sepanjang 2,64 cm dan 4,75 cm (kuadran 1), retakan sepanjang 3,81 (kuadran 2), retakan sebesar $1,31 \mathrm{~cm}$ (kuadran 4), Lubang besi dengan diameter $0,5 \mathrm{~cm}$, titiktitik hitam dan warna lead apron yang tidak homogen. Lead apron 2 mengalami kerusakan berupa retakan sepanjang 4,64 cm (kuadran 1), retakan sepanjang 10,31 $\mathrm{cm}$ dan 5,66 cm (kuadran 2), retakan sepanjang 3,81 $\mathrm{cm}$ dan 1,57 (kuadran 4), titik-titik hitam dan warna lead apron yang tidak homogen. Pada lead apron 3,4,5, tidak ditemukan adanya kerusakan, hanya saja terlihat adanya lekukan namun masih dalam batas normal. Pada lead apron 6 terdapat adanya lekukan, lipatan yang menimbulkan adanya robekan sepanjang $1,5 \mathrm{~cm}$ dan $0,85 \mathrm{~cm}$ pada kuadran 4 belakang, robekan tersebut masih dalam batas normal. Sedangkan lead apron 7 tidak ditemukan adanya kerusakan hanya saja terdapat warna lead apron yang tidak homogen.

Berdasarkan teori Lambert (2001), 2 buahlead apron berwarna coklat yang dibeli pada tahun 1997 sudah tidak dapat digunakan lagi karena terdapat kerusakan berupa retakan yang melebihi dari $15 \mathrm{~mm}^{2}$ pada organ vital, sehingga lead apron tersebut tidak mampu menerapkan asas proteksi radiasi. Sedangkan 5lead apron lainnya masih dikatakan layakkarena tidak ada kerusakan yang melebihi dari batas normal maksimum lead apron dinyatakan rusak. Sehingga lima lead apron ini mampu menerapkan prinsip asas proteksi radiasi.

Pada hasil pengujian secara menyeluruh didapatkan hasil dengan mayoritas lead apron mengalami banyak lekukan dan warna lead apron yang tidak homogen. Menurut penulis, lekukan yang ada pada lead apron dapat disebabkan karena penyimpanan, perawatan yang kurang baik dan rutinitas pemakaian lead apron. Sedangkan warna yang tidak homogen pada lead apron dapat dikarenakan oleh umur lead apron yang sudah lama.

Meskipun secara visual terlihat baik, kondisi penyusun lead apron belum tentu terlihat baik tanpa adanya pengujian secara berkala. Dengan hasil pengujian ini dapat digunakan sebagai pedoman dalam pengujian periode selanjutnya untuk mengetahui keadaan integritas (kerusakan-kerusakan atau penurunan kualitas) lead apron setelah dilakukan perbaikan dalam pemeliharaan dan perawatan dengan baik. Sebaiknya pengujian lead apron dilakukan secara berkala yaitu 1218 bulan sekali untuk mengetahui kondisi lead apron atau sesuai dengan kebutuhan. Serta Standar Operasional Prosedur (SOP) pengujian lead apron sebagai pedoman pengujian lead aron di Instalasi Radiologi Rumah Sakit Roemani Muhammadiyah Semarang. Selanjutnya berdasarkan hasil pengujian lead apron maka dapat dibuat tabel kelayakan lead apron yaitu :

\section{Simpulan}

2 dari 7 lead apron dinyatakan tidak layak. Sedangkan 5 lainnya masih dapat dikatakan layak pakai. Selanjutnya dapat diperoleh prosentase berdasarkan jumlah layak dan tidaknya lead apron yaitu 5 buah lead 
apron $(71 \%$ )dalam kondisi layak dan 2 buah lead apron $(29 \%)$ dalam kondisi tidak layak.

cara perawatannya, tidak ada perawatan khusus pada lead apron. Jika terdapat tumpahan media kontras, darah maupun kotoran lain cukup dibersihkan dengan alkohol maupun air. Pembersihan tidak dilakukan secara periodik, hanya ketika terdapat kotoran saja.

\section{Saran}

Sebaiknya untuk menjaga fungsi dan keawetan lead apron lebih diperhatikan lagi cara pemeliharaan dan perawatannya. Pemeliharaan dilakukan dengan cara menyimpan seluruh lead apron tersebut pada rak khusus secara horizontal agar tidak rusak akibat gravitasi dan mengalami penurunan fungsi.

Sebaiknya dilakukan pengujian lead apron secara berkala yaitu 12-18 bulan sekali untuk mengetahui kondisi lead apron tersebut. Hasil pengujian didokumentasikan untuk perbandingan hasil pengujian tahap selanjutnya.

Perlu adanya Standar Operasional Prosedur (SOP) pengujian lead apron sebagai pedoman pengujian lead apron di Instalasi Radiologi Rumah Sakit Roemani Muhammadiyah Semarang.

Pemberian tanda pada lead apron yang sudah mengalami beberapa tanda kerusakan agar dapat diketahui letak kerusakan dan agar lebih hati-hati dalam peggunaannya.

\section{Daftar Pustaka}

Akhadi, Mukhlis, 2000. Dasar-Dasar Proteksi Radiasi. Jakarta: Rineka Cipta.

Australian Radiation Protection and Nuclear Safety Agency, 2015. Aprons for Protection Agains XRays.

Batan, 2005. Pengenalan radiasi. Jakarta www.batan.go.id diakses pada 20 Januari 2018 pukul 19.03

Bushong, SC, 2013 Radiologic Science For Technologist. Baylor college of medicine, Houston, Texas

Grover, SB., Kumar,J Gupts, A, Khansa,L Protection agains radiation hazard: regulatory bodies, safety norms, does limits and protection device. Departement of Radiology,Vardhaman Mahavir Medical College \& Safdarjang Hospital India.

Indrati R dkk, 2017 Proteksi Radiasi Bidang Radiodiagnostik dan Intervensional.Inti Medika Pustaka.

Lambert, Kent, Mc Keon, Tara, 2001 Inspection of lead aprons: Criteria for Radiation. Streets.Philadelpia.

Lloyd, Peter J, 2001. Quality Assurance workbook for radiographer \& radiological technologist. Diagnostic Imaging and LaboratoryTechnology. WHO. Geneva.
Oyar, Orhan, Arzu, K, 2012. How protective are the lead apron we use against ionizing radiation?. Izmir Celebi University. Turkey.

Perka BAPETEN no 8 tahun 2011 tentang keselamatan Radiasi dalam Penggunaan Pesawat Sinar-X Radiologi Diagnostik dan Intervensional.

Pratama B, 2014. Pengujian lead apron di Instalasi Radiologi Rumah Sakit Roemani Muhammadiyah Semarang.

Radiology Compliance Branch. 2011. The Use and Care of Lead Protective Equipment.

Rasad, Sjahriar, 2005. Radiologi Diagnostik Jakarta: FK.UI.

Rincorp, 2011. Soothe-guard air lead free radiography aprons. www.rinncorp.com diakses pada tanggal 17 Desember 2017 pukul 20.18 WIB.

Rohmah, 2015. Pengujian lead apron di Instalasi Radiologi RSU RA Kartini Jeapa.

Roser H.W 2010. Quality Assurance of X-ray Protection Cloting at the University Hospital Basel

Stanford University, 2018 Lead Apron Inspection and Inventory

Policy.https://ehs.stanford.edu/manual/radiationprotection-guidance-hospital-staffllead-aproninspection-and-inventory-policy diaksespada 15 Juli 2018 pukul 16.58 WIB.

Victorian Goverment, 2011. Testing lead aprons used in diagnostic radiology departement.Melbourne.

Yulihendra, 2002. Alat Proteksi Diri.http://digilib.unimus.ac.id/files/disk1/113/jtpt unimus-gdl-yulihendra-5638-3-babii.pdf diakses pada 17 Desember 2017 pukul 21.05 WIB. 